\title{
Cost effectiveness of 'on demand' HIV pre-exposure prophylaxis for non-injection drug-using men who have sex with men in Canada
}

\author{
Estelle Ouellet MPA MD(c), Madeleine Durand MD MSc FRCPC, Jason R Guertin MSc PhD(c), \\ Jacques LeLorier MD PhD FRCPC FISPE, Cécile L Tremblay MD FRCPC
}

\begin{abstract}
E Ouellet, M Durand, JR Guertin, J LeLorier, CL Tremblay. Cost-effectiveness of 'on demand' HIV pre-exposure prophylaxis for non-injection drug-using men who have sex with men in Canada. Can J Infect Dis Med Microbiol 2015;26(1):23-29.
\end{abstract}

BACKGROUND: Recent trials report the efficacy of continuous tenofovir-based pre-exposure prophylaxis (PrEP) for prevention of HIV infection. The cost effectiveness of 'on demand' PrEP for noninjection drug-using men who have sex with men at high risk of HIV acquisition has not been evaluated.

OBJECTIVE: To conduct an economic evaluation of the societal costs of HIV in Canada and evaluate the potential benefits of this PrEP strategy. METHODS: Direct HIV costs comprised outpatient, inpatient and emergency department costs, psychosocial costs and antiretroviral costs. Resource consumption estimates were derived from the Centre Hospitalier de l'Université de Montréal HIV cohort. Estimates of indirect costs included employment rate and work absenteeism. Costs for 'on demand' PrEP were modelled after an ongoing clinical trial. Costeffectiveness analysis compared costs of 'on demand' PrEP to prevent one infection with lifetime costs of one HIV infection. Benefits were presented in terms of life-years and quality-adjusted life-years.

RESULTS: The average annual direct cost of one HIV infection was $\$ 16,109$ in the least expensive antiretroviral regimen scenario and $\$ 24,056$ in the most expensive scenario. The total indirect cost was $\$ 11,550$ per year. Total costs for the first year of HIV infection ranged from $\$ 27,410$ to $\$ 35,358$. Undiscounted lifetime costs ranged from $\$ 1,439,984$ ( $\$ 662,295$ discounted at $3 \%$ and $\$ 448,901$ at $5 \%$ ) to $\$ 1,482,502$ ( $\$ 690,075$ at $3 \%$ and $\$ 485,806$ at $5 \%$ ). The annual cost of PrEP was $\$ 12,001$ per participant, and $\$ 621,390$ per infection prevented. The PrEP strategy was cost-saving in all scenarios for undiscounted and 3\% discounting rates. At 5\% discounting rates, the strategy is largely cost-effective: according to least and most expensive scenarios, incremental cost-effectiveness ratios ranged from $\$ 60,311$ to $\$ 47,407$ per quality-adjusted life-year.

CONCLUSION: This 'on demand' PrEP strategy ranges from costsaving to largely cost-effective. The authors believe it represents an important public health strategy for the prevention of HIV transmission.

Key Words: Cost effectiveness; HIV; Prophylaxis

\section{La rentabilité de la prophylaxie préexposition du VIH sur demande au Canada pour les hommes qui ne consomment pas de drogues injectables, mais qui ont des relations sexuelles avec d'autres hommes}

HISTORIQUE : De récents essais rendent compte de l'efficacité d'une prophylaxie préexposition continue à base de ténofovir $(\mathrm{PrEP})$ pour prévenir l'infection par le VIH. La rentabilité de la PrEP sur demande n'a pas été évaluée chez les hommes qui ne consomment pas de drogues injectables, mais qui ont des relations sexuelles avec d'autres hommes très susceptibles de contracter le VIH.

OBJECTIF : Réaliser une évaluation économique des coûts du VIH pour la société au Canada et évaluer les avantages potentiels de cette stratégie de PrEP.

MÉTHODOLOGIE : Les coûts directs du VIH incluaient les coûts des rendez-vous ambulatoires, des séjours hospitaliers et des visites à l'urgence, les coûts psychosociaux et les coûts des antirétroviraux. Lévaluation de la consommation des ressources était dérivée de la cohorte de VIH du Centre hospitalier de l'Université de Montréal. Les évaluations des coûts indirects incluaient le taux d'emploi et l'absentéisme au travail. Les coûts de la PrEP sur demande reprenaient le modèle d'un essai clinique en cours. Lanalyse de rentabilité reposait sur une comparaison des coûts de la PrEP sur demande pour prévenir une infection avec les coûts de traitement à vie d'une infection par le VIH. Les avantages étaient présentés d'après les années de vie et les années de vie pondérées par la qualité.

RÉSULTATS : Le coût direct annuel moyen d'une infection par le VIH s'élevait à 16109 \$ d'après le scénario de posologie antirétrovirale le moins coûteux, et à 24056 d'après le scénario le plus coûteux. Le coût indirect total s'élevait à 11550 \$ par année. Les coûts totaux pour la première année d'infection par le VIH oscillaient entre 27410 \$ et 35358 \$. Les coûts de traitement à vie non actualisés variaient entre $1439984 \$(662295$ \$ actualisés à $3 \%$ et 448901 \$, à $5 \%)$ et 1482502 \$ (690 075 \$ à $3 \%$ et 485806 \$ à $5 \%$ ). Le coût annuel de la PrEP était de 12001 \$ par participant, et de 621390 \$ par infection prévenue. La stratégie de PrEP était économique dans tous les scénarios non actualisés et actualisés à $3 \%$. Dans les scénarios actualisés à $5 \%$, la stratégie était largement rentable. En effet, selon les scénarios le moins et le plus coûteux, le rapport coût-efficacité différentiel se situait entre 60311 \$ et 47407 \$ par année de vie pondérée par la qualité.

CONCLUSION : Cette stratégie de PrEP sur demande se situe quelque part entre la production d'économies et une rentabilité substantielle. Les auteurs sont d'avis qu'elle représente une importante stratégie de santé publique pour prévenir la transmission du VIH.

(1), and show the limitations of our current prevention strategies. In Canada, the proportion of new HIV infections among MSM in 2011 was higher than in 2008. Of the 73,000 individuals living with HIV

\footnotetext{
$\mathrm{A}$ lthough there has been a decrease in new HIV infections worldwide, increases in new HIV infections among non-injection drug-using (IDU) men who have sex with men (MSM) are concerning
}

Centre de Recherche du Centre Hospitalier de l'Université de Montréal, Montréal, Québec

Correspondence and reprints: Dr Cécile Tremblay, Laboratoire de santé publique du Québec, Institut national de santé publique du Québec, 20045 chemin Sainte-Marie, Sainte-Anne-de-Bellevue, Quebec H9X 3R5. Telephone 514-457-2070 ext 235, fax 514-457-6346, e-mail c.tremblay@umontreal.ca 
in Canada, almost one-half (46.7\%) are MSM (2). Continuous preexposure prophylaxis $(\mathrm{PrEP})$ is a promising approach for the prevention of HIV infection in combination with other prevention strategies. Recent clinical trials have shown that such PrEP, administered continuously on a daily basis, can reduce the risk of infection, although results vary according to the patient population studied and adherence to treatment (3-7).

In an effort to improve PrEP efficacy (treatment adherence and limit exposure to drugs), researchers have developed PrEP strategies other than administering them on a daily basis. One of these strategies is 'on demand' PrEP administration. An Agence Nationale de Recherche sur le SIDA-sponsored, randomized, double-blinded, placebocontrolled PrEP clinical trial that targets non-IDU MSM at high risk for HIV acquisition evaluated this strategy (8). The 'on demand' protocol entails taking the drug $24 \mathrm{~h}$ before the first sexual encounter, every $24 \mathrm{~h}$ during the sexual activity and $24 \mathrm{~h}$ after the last sexual encounter. It may require more planning than administration on a daily basis, but could lead to inferior drug consumption per month depending on the level of sexual activity of the participant. This drugbased intervention, referred to as Intervention Préventive de l'Exposition aux Risques avec et pour les hommes Gays (IPERGAY), is accompanied by intense counselling on safe sex as well as condom distribution. IPERGAY is the first trial aiming to establish the efficacy of 'on demand' PrEP. While the clinical trial is underway both in France and in Canada, our objective is to provide an economic evaluation from a societal perspective of costs of HIV in Canada because health care costs vary according to jurisdictions, and to evaluate the potential benefits of this 'on demand' PrEP strategy (if it is effective).

\section{METHODS}

Microcosting methods similar to those used in other HIV prevention studies $(9,10)$ were applied. All costs are reported in 2012 Canadian dollars (USD $\$ 0.98, € 0.77$ ). The cost of preventing one infection was compared with the lifetime cost of one HIV infection. This approach is recommended by the Centers for Disease Control and Prevention (CDC; Georgia, USA): "The lifetime treatment cost of an HIV infection can be used as a conservative threshold value for the cost of averting one infection" (11).

\section{Costs of HIV infection}

To model the costs of HIV infections, an inventory of all health care inputs consumed during the course of HIV disease was created. The Centre Hospitalier de l'Université de Montréal (CHUM) HIV cohort database was used, for which administrative as well as clinical data are collected on all individuals on a per-visit basis. These patients were treated according to Quebec guidelines (12). Data from all HIVinfected homosexual male non-IDUs were included in the present study because high-risk non-IDU MSM is the population targeted by the 'on demand' PrEP intervention of interest.

Direct medical costs: Direct HIV patient care costs comprised five broad categories: outpatient care, inpatient care, emergency department care, psychosocial care and antiretroviral therapy (ART). For outpatient care, subcategories included personnel costs, laboratory testing and overhead costs. For personnel costs, time spent and wages for nursing services were included (13), as well as fee-for-service billing from doctors (14). During the first visit, laboratory testing included complete blood count, CD4 count, viral load, viral genotyping, HLAB5701 genotype, lipid profile, kidney and liver function tests, urine test, blood glucose test, sexually transmitted disease (syphilis, chlamydia, gonorrhoea) tests, hepatitis, varicella and toxoplasmosis serology, as well as tuberculosis testing (15). Follow-up visits included complete blood count, CD4 count, kidney and liver function tests, and viral load. For the inpatient and emergency department categories, average physician fee-for-service (14) and operating cost were included (16). For the psychosocial care, the hourly wages of social workers and psychologists were included (16). For ART, drug costs and pharmacist dispensing fees were included (17).
Primary data on the number and type of resources consumed were collected from the CHUM database (722 patients). Resource utilization was first measured by calculating the annual average visits (or hospitalization days) per patient. This resource utilization indicator was multiplied by unit costs to obtain the total annual average resource costs per patient. This procedure was performed for the first four direct HIV patient care costs categories. For ART, the costs of antiretrovirals and pharmacist dispensing fee were summed. The total cost was presented as the average annual cost of ART per patient. The costs of different therapy lines was taken into consideration in the cost-effectiveness analysis. From a drug-acquisition perspective, the least expensive scenario was established with Atripla ${ }^{\mathrm{TM}}$ (Gilead Sciences Inc, USA) (the least expensive first-line therapy) and the most expensive scenario with the combination of Prezista ${ }^{\mathrm{TM}}$ (Janssen Therapeutics, USA), Norvir ${ }^{\mathrm{TM}}$ (Abbvie Inc, USA) and Truvada ${ }^{\mathrm{TM}}$ (Gilead Sciences Inc, USA) (the most expensive first-line therapy). Due to suggestions in recent literature, it was assumed that after one year of ART, the efficiency of a first-line regimen is compromised due to nonadherence and the development of drug resistance (18). Therefore, the introduction of second-line therapy (Isentress ${ }^{\mathrm{TM}}$ (Merck \& Co, Inc, USA), Intelence ${ }^{\mathrm{TM}}$ (Janssen Therapeutics, USA), Norvir and Prezista) was initiated at year 1 after diagnosis. At year 1 , $20 \%$ of patients failed the first-line regimen; at year 2, 25\% cessed first-line; and starting at year 3, incremental declines of $10 \%$ per year were estimated until year 10 , when $100 \%$ of patients had made the switch to second-line therapy.

Indirect costs: Indirect HIV infection costs comprised two categories: lost revenue due to employment rate gap; and work absenteeism.

The gap in employment rate was estimated by using the difference in employment rate between the general male population in Quebec (19) and the HIV-positive homosexual male population in Ontario (A Burchell, personal communication, April 30, 2013). This was believed to be a good approximation of the gap between the male homosexual and HIV-positive male homosexual population because the literature indicates that there is no difference in the employment rate in Canada between the general male population and the homosexual male population (20). Ontario data for employment rate (21) were used because the employment rate for HIV-positive homosexual males in Quebec was unavailable. The employment rate has been systematically lower in Quebec than in Ontario since 1976 (except for the 15- to 24-year-old age group, but this comprises only $7 \%$ of the HIV-positive population in Quebec) $(21,22)$. Thus, using the Ontario data gives a conservative estimate of productivity losses in Quebec. To calculate lost revenue, the age structure for both employment rate and wages (Quebec data) were taken into consideration (19).

In terms of work absenteeism, it was assumed that each outpatient/ psychosocial visit necessitates $4 \mathrm{~h}$ and inpatient/emergency care visit leads to $8 \mathrm{~h}$ of missed work per day. The annual average hours of missed work per patient in the CHUM cohort was multiplied by the average hourly wage for three age groups ( 15 to 24 years, 25 to 54 years and $\geq 55$ years) (23).

\section{Costs of the intervention: 'on demand' PrEP}

To model the costs of 'on demand' PrEP, the intervention proposed in the IPERGAY clinical trial protocol was used (8).

Direct costs: The costs of IPERGAY PrEP strategy includes six outpatient visits per year, including nursing costs, laboratory testing and overhead costs, as described above. The annual cost of Truvada (17), the prophylactic drug provided, was added to the total costs, as well as the cost of condoms supplied at each visit. The most expensive scenario of the 'on demand' Truvada was used in the present analysis. This scenario entails a level of sexual activity that requires drug administration on a daily basis.

Indirect costs: For the indirect costs, it was estimated that $4 \mathrm{~h}$ of work would be missed for each outpatient visit. These $24 \mathrm{~h}$ of work missed per year were then multiplied by the average hourly wage (23) weighted by the age distribution of male workers and their employment rate (19) to obtain the average annual indirect cost per patient for participating to the 'on demand' PrEP intervention. 
TABLE 1

Annual cost of HIV infection per patient $(2012 \$)$

\begin{tabular}{|c|c|c|}
\hline Direct cost & Average annual costs per patient* & Reference \\
\hline Outpatient: first visit & $\$ 683$ & MSSS (16) \\
\hline Outpatient: follow-up & $\$ 272$ & MSSS (16) \\
\hline Outpatient total & $\$ 934$ & MSSS (16) \\
\hline Emergency department visits & $\$ 116$ & MSSS (16), CHUM database \\
\hline Social worker & $\$ 14$ & MSSS (16), CHUM database \\
\hline Psychologist & $\$ 39$ & MSSS (16), CHUM database \\
\hline HIV medication (least/most expensive) & $\$ 14,093 / \$ 22,040$ & RAMQ (17) \\
\hline Hospitalization & $\$ 913$ & MSSS (16),CHUM database \\
\hline Total direct cost (least/most expensive) & $\$ 16,109 / \$ 24,056$ & \\
\hline Indirect cost & Average annual costs per patient ${ }^{\dagger}$ & Reference \\
\hline $\begin{array}{l}\text { Average annual salary losses due to unemployement, weighted according to age } \\
\text { distribution }\end{array}$ & $\$ 10,925$ & $\begin{array}{l}\text { A Burchell (personal } \\
\text { communication, April 30, 2013), } \\
\text { INSPQ (22), CANSIM (23) }\end{array}$ \\
\hline $\begin{array}{l}\text { Average annual productivity cost due to medical follow-up, weighted according to } \\
\text { age distribution }\end{array}$ & $\$ 625$ & CANSIM (19), INSPQ (22) \\
\hline Total indirect costs & $\$ 11,550$ & \\
\hline Total costs (least/most expensive) & $\$ 27,659 / \$ 35,606$ & \\
\hline
\end{tabular}

${ }^{*}$ Calculated by multiplying the average annual visits distributed on sample by unit cost. See Supplementary Tables 1 and 3 for more details; †See Supplementary Tables 2, 3 and 5 for more details. MSSS Ministère de la santé et services sociaux du Québec; RAMQ Régie de l'assurance maladie du Québec; INSPQ Institut national de santé publique du Québec; CANSIM Statistics Canada socioeconomic database

\section{Cost to prevent one infection}

The cost of preventing one infection reflects the annual average cost of the 'on demand' PrEP intervention required to avert one infection. This annual average cost is proportional to the number of participants of the 'on demand' PrEP intervention needed to prevent one infection. To estimate this number of participants, it was hypothesized that the number needed to treat (NNT) derived from the clinical trial conducted by Grant et al (4) would be equivalent to the NNT in the IPERGAY trial. The Grant et al (4) clinical trial tested continuous Truvada PrEP for high-risk homosexual males. It was anticipated that PrEP efficacy would be improved by increasing treatment adherence and limiting exposure to drugs with the 'on demand' PrEP strategy. In this context, it was believed to be appropriate to assume a NNT equivalent to, if not lower than the one derived from the Grant et al (4) trial. This NNT of 51.78 was based on the event rate of the control group (5\%) and of the PrEP group (3\%), and was adjusted for the length of the Grant et al (4) clinical trial (1.2 years). The cost of preventing one infection is obtained by multiplying the annual cost per participant of the 'on demand' PrEP intervention by the NNT.

\section{Cost-effectiveness analysis}

The cost-effectiveness analysis guidelines suggested by the CDC (11) were followed to provide an economic understanding of the societal costs of HIV in Canada and the potential benefits of this 'on demand' PrEP strategy. The annual cost of the 'on demand' PrEP intervention to prevent one infection was first compared (using the NNT) with the total cost of an HIV infection. The total cost of HIV infection was the annual societal cost of an HIV infection multiplied by the life expectancy of HIV-positive individuals diagnosed at 30 years of age. Thirty years of age is the median age group with the highest rates of new diagnosis in the past five years in Quebec (22). Life expectancy for an individual diagnosed at this age is 35.2 years, according to a collaborative analysis of 14 cohort studies (24).

The benefits were also presented in terms of life-years and qualityadjusted life years (QALY). Using the concept of utilities, life-years were adjusted to the asymptomatic HIV health state. A meta-analysis by Tengs and Lin (25) indicates that one year of life for an asymptomatic HIV patient is equivalent to 0.94 of one year of life for a healthy individual. The lifetime societal cost of an HIV infection and benefits (life-years and QALY) was presented as undiscounted, and discounted at $3 \%$ and $5 \%$, in accordance with the Canadian guidelines for the
TABLE 2

Annual costs of 'on demand' PrEP strategy per participant (2012 \$)

\begin{tabular}{lll}
\hline & Cost & Reference \\
\hline $\begin{array}{l}\text { Outpatient visits } \\
\begin{array}{l}\text { Medication (tenofovir/ } \\
\text { emtricitabine) }\end{array}\end{array}$ & $\$ 2,041^{*}$ & MSSS (16) \\
$\begin{array}{l}\text { Condoms } \\
\text { Work absenteeism }\end{array}$ & $\$ 405^{*}$ & RAMQ (17) \\
& $\$ 408^{\dagger}$ & $\begin{array}{l}\text { CANSIM (19) }{ }^{\ddagger} \text {, INSPQ } \\
(22)\end{array}$ \\
$\begin{array}{l}\text { Costs per participant } \\
\text { Costs per infection prevented }\end{array}$ & $\$ 12,001$ & \\
\hline
\end{tabular}

*See Supplementary Table 1 for more details; ' See Supplementary Table 4 for more details; $¥$ Statistics Canada socioeconomic database; INSPQ Institut national de santé publique du Québec; MSSS Ministère de la santé et services sociaux du Québec; RAMQ Régie de l'assurance maladie du Québec

economic evaluation of health interventions (26). Because all costs incurred with the 'on demand' PrEP intervention are limited to the first year of follow-up, no discounting is required. As such, both discounted and undiscounted amounts will remain the same.

\section{RESULTS}

Direct and indirect costs of an HIV infection

Table 1 presents the annual cost of an HIV infection. The average annual direct cost of an HIV infection was $\$ 16,109$ in the least expensive scenario and $\$ 24,056$ in the most expensive scenario (most expensive first-line ART). The total indirect cost was $\$ 11,550$. The average annual salary loss due to unemployment, weighted by age distribution, was $\$ 10,925$, representing $95 \%$ of the indirect cost of an HIV infection. Indirect costs calculation details are presented in the supplementary data. In the least expensive scenario, the total cost for the first year of HIV infection was $\$ 27,659$. In the most expensive scenario, the cost was $\$ 35,606$. With the second-line therapy introduced fully at year 10 of infection, the cost of HIV infection increased to $\$ 42,197$.

When multiplied by life expectancy at 30 years of age, the least expensive scenario with undiscounted lifetime costs was $\$ 1,439,984$ (\$662,295 discounted at $3 \%$ and $\$ 448,901$ at $5 \%$ ), and the most expensive scenario with undiscounted lifetime costs was $\$ 1,482,502$ ( $\$ 690,075$ at $3 \%$ and $\$ 485,806$ at $5 \%$ ). 
TABLE 3

Cost-effectiveness analysis for prevention of an infection acquired at 30 years of age (2012\$)

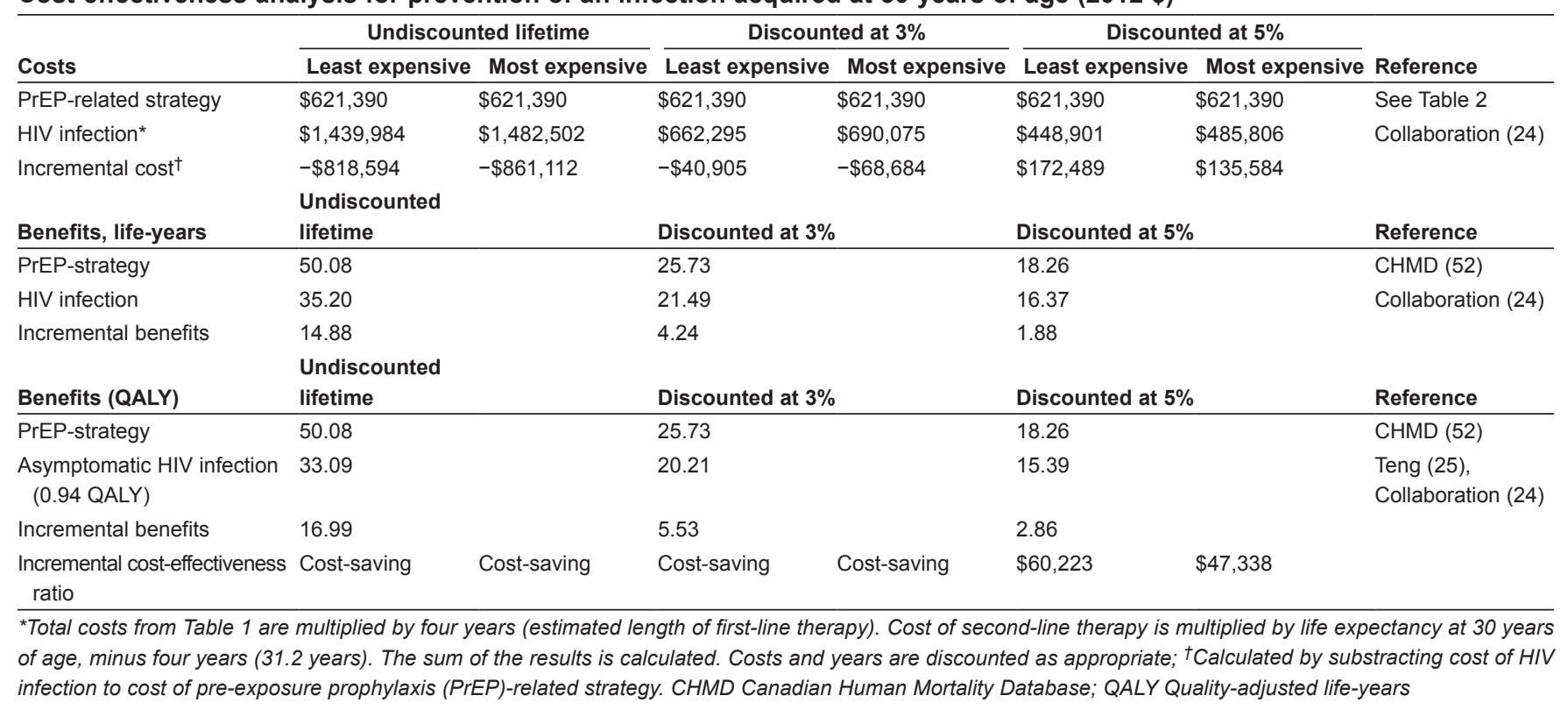

Cost of 'on demand' PrEP intervention

As shown in Table 2, the annual cost of 'on demand' PrEP intervention as defined in the IPERGAY clinical trial was $\$ 12,001$ per participant, and $\$ 621,390$ per infection prevented.

\section{Cost-effectiveness analysis}

Table 3 presents the results of the cost-effectiveness analysis of the least and most expensive costing scenarios. At $\$ 621,390$, the cost per infection prevented was lower than the undiscounted lifetime costs of an HIV infection by $-\$ 818,594(-\$ 40,905$ at $3 \%$ and $+\$ 172,489$ at $5 \%)$ in the least expensive scenario. In the most expensive scenario, the cost per infection prevented was lower than the undiscounted lifetime costs of an HIV infection by $-\$ 861,112(-\$ 68,684$ at $3 \%$ and $+\$ 135,584$ at $5 \%)$. The undiscounted benefits of preventing an infection were of almost 15 life-years gained ( 4.24 at $3 \%$ and 1.88 at $5 \%$ ). When adjusted for the quality of life, the undiscounted benefits of preventing an infection were of almost 17 QALY (5.53 at 3\% and 2.86 at 5\%). The IPERGAY strategy was cost-saving in all scenarios, except when discounted at $5 \%$, when the incremental cost effectiveness ratio was $\$ 60,223$ and $\$ 47,338$ per QALY in the least and most expensive scenarios, respectively.

Sensitivity analysis

The analysis of the efficiency of a first-line regimen was also performed based on a different assumption. Second-line therapy for $100 \%$ of patients was introduced at year 4 after diagnosis. The number derived from this assumption lead to results similar to those presented in Table 3. At $\$ 621,390$, the cost per infection prevented was lower than the undiscounted lifetime costs of an HIV infection by $-\$ 406,977$ $(-\$ 20,575$ at $3 \%$ and $+\$ 193,231$ at $5 \%)$ in the least expensive scenario. In the most expensive scenario, the cost per infection prevented was lower than the undiscounted lifetime costs of an HIV infection by $-\$ 438,766(-\$ 51,001$ at $3 \%$ and $+\$ 163,641$ at $5 \%)$.

Table 3 presents the cost-effectiveness analysis of infections prevented at 30 years of age. Analysis of infections prevented at 20 and 40 years of age was also performed. The rate of new diagnosis among the 15 to 24 years of age group is significantly higher than the rate among the 35 to 44 years of age group. However, the latter age group has historically had the highest new diagnosis rate (22). Life expectancy for individuals diagnosed at 20 years of age is 43.1 years, and is 28.3 years for a diagnosis made at 40 years of age (24). At 20 years of age, the cost per infection prevented in the least expensive scenario was lower than the undiscounted lifetime costs of a HIV infection by $-\$ 651,050(-\$ 40,641$ discounted at $3 \%$ and $+\$ 176,511$ at $5 \%$ ). In the most expensive scenario, the cost per infection prevented was lower than the undiscounted lifetime costs of a HIV infection by $-\$ 682,839$ ( $-\$ 71,068$ at $3 \%$ and $+\$ 146,922$ at $5 \%)$. At 40 years of age, the cost per infection prevented in the least expensive scenario was lower than the undiscounted lifetime costs of a HIV infection by $-\$ 193,800(+\$ 143,256$ discounted at $3 \%$ and $+\$ 211,641$ at $5 \%)$. In the most expensive scenario, the cost per infection prevented was lower than the undiscounted lifetime costs of an HIV infection by $-\$ 225,589(+\$ 112,829$ at $3 \%$ and $+\$ 182,052$ at $5 \%)$.

\section{DISCUSSION}

Antiretroviral drugs can be used to prevent HIV transmission. Universal HIV testing to enhance the identification of HIV-positive individuals followed by immediate treatment of all HIV-positive individuals can yield substantial benefits to individuals and affect the dynamics of HIV transmission $(27,28)$. However, the deployment of such a program, with its extensive breadth and depth, presents a formidable challenge (29). ART can also be used to protect uninfected individuals both before and after exposure to HIV infection. Several public health authorities have recommended the use of $\mathrm{PrEP}$ as part of a comprehensive prevention package to decrease HIV transmission $(30,31)$. Although some studies have shown the PrEP could be cost-effective in certain settings, particularly in high-risk individuals, it is important to estimate the impact of such strategies in a universal health care setting, where allocation of scarce resources needs to target the most effective strategies. In this context, 'on demand' PrEP compared with continuous PrEP may be an interesting approach, limiting the use and cost of drugs with the potential of preventing similar numbers of infections. This strategy is being evaluated in France and in Canada, and we aimed to evaluate its potential cost effectiveness in our universal health care system.

Very few studies have estimated the cost of HIV infection in Canada $(32,33)$. Our costing estimates are in agreement with these studies. Krentz et al (32) estimated the 2006 total direct costs of an HIV infection to be $\$ 13,908$ per patient. The Canadian AIDS society estimated the 2009 lifetime costs of an HIV infection to be $\$ 1.3$ million per person (33). In the United States, the most recent estimates cited by the CDC come from a 2006 study by Schackman et al (34). Schackman et al estimated the undiscounted lifetime direct HIV treatment costs to be $\$ 618,900$ in 2004. In 2012, our undiscounted lifetime direct HIV treatment costs estimate was $\$ 1,028,367$. Our data suggest 
that 'on demand' PrEP, modelled assuming the same level of success as the IPERGAY trial, can be cost-saving because the net benefits (lifeyears and QALY) of the intervention are greater than current standards of care, and the cost of the intervention is less than the lifetime cost of an infection undiscounted and discounted at a 3\% rate (11). The incremental cost-effectiveness ratio of the lifetime costs of an infection discounted at a $5 \%$ rate was largely cost effective. There is some consensus in discounting practice in health economics evaluations: both public and health professional tend to choose lower discount rates in health-related comparisons than in finance-related comparisons (35). We followed the Panel on Cost-Effectiveness in Health and Medicine recommendation and use the 3\% discount rate in the reference case $(36,37)$, but we also present the $5 \%$ discount rate. Moreover, our results are consistent with the majority of previous modelling work on the cost-effectiveness of PrEP interventions among MSM. Most authors found PrEP to be cost-effective when targeting high-risk MSM (6,38-41). However, the models used and costing of HIV infection/PrEP interventions vary considerably among authors.

One could argue that the first dimension of our cost-effectiveness analysis is not consistent in terms of time frame, presenting the costs for one year of 'on demand' PrEP versus 35.2 years of infection. We chose to analyze our results this way because we could not predict how many years a participant would use the program. However, once an individual is infected, he becomes HIV-positive for the rest of his life. We were comfortable presenting the results in this manner because in a riskmanagement perspective, the IPERGAY strategy has fixed and, thus, predictable costs over a certain period of time, whereas HIV infection costs are harder to estimate over time because they are and will be variable. Moreover, the CDC states that "the lifetime treatment cost of an HIV infection can be used as a conservative threshold value for the cost of averting one infection" (11). Furthermore, we considered a Markov chain model not feasible, given that transition probabilities for the current situation are not available in the published literature.

The possibility that PrEP could result in increased risk-taking behaviour (ie, increased unprotected sex, number of partners, etc) with accompanying increases in health care costs was not factored into our analysis. Although the literature does not provide a definite consensus on behavioral changes (42-50), the importance of behavioral interventions to accompany any wide-scale provision of PrEP to high-risk populations is underscored. In the IPERGAY trial, intensive counselling on the importance of safe sex and condom distribution is provided. Moreover, the participants are selected assuming that they do not use condoms consistently and have multiple partners. The cost of emerging resistance to Truvada was not included in our analysis because recent clinical trials failed to show any cases, suggesting that the percentage of emerging drug resistant cases would be negligible $(3-5,49,50)$.

The main limitation of our costing methodology relies in our estimates of indirect costs. We focused on the impact of morbidity on productivity losses instead of mortality because of the prolonged life expectancy since the arrival of highly active ART. Nevertheless, some authors still chose to measure the income foregone because of mortality $(33,51)$. Also, the impact of morbidity on productivity could have been better estimated by a presenteeism indicator and by taking into account volunteer time and patient/family leisure time. It would have been preferable to control for variables that influence wages (ie, level of education, type of employer, years of experience, geographical location, etc.) to estimate costs related to productivity losses, but such comprehensive datasets were not available. However, we are confident that these estimates present a more accurate picture of HIV costs to society than if we had not included them (9). Another limitation of the present study is that we were unable to estimate the non-ART drugs costs, although according to the Krentz and Gill (32) study, they should be considered to be negligible. The out-of-pocket expenses (ie, copayment) for which we could not provide any estimates should be evaluated. Even if the database from medical sites outside Montréal were not accessible, we are confident that the CHUM sample is representative of health care resource utilization in the province of Quebec because the majority $(62.1 \%)$ of declared cases within the MSM population since 2002 are Montreal residents (22). Although CHUM's non-IDU MSM HIVpositive patients database may be biased toward sicker patients, it captures the entire spectrum of health services that may be used during the course of an HIV infection, which would not be the case if we used databases from community HIV clinics.

In the context of an eventual wider implementation of the program following CDC/WHO guidelines $(30,31)$, health care resource utilization may have slightly been underestimated because the MSM-IDU HIV-positive population was excluded from our analysis to abide by the IPERGAY protocol. The results of this cost-effectiveness analysis should not be generalized to other populations such as IDU or serodiscordant couples for whom PrEP is recommended by the CDC/WHO, given that the rates of HIV acquisition are lower than for the MSM group $(2,22)$.

\section{SUPPLEMENTARY TABLE 1} Direct cost, 2012 \$

\begin{tabular}{|c|c|c|}
\hline Cost inputs & Unit cost & Reference \\
\hline \multicolumn{3}{|l|}{ Outpatient care } \\
\hline Overhead costs & $\$ 40.92$ per visit & $\begin{array}{l}\text { Annexe à la circu- } \\
\text { laire 2013-028 (16) }\end{array}$ \\
\hline Physician, general practicioner & $\$ 55.00$ per visit & RAMQ (14) \\
\hline Physician, specialist & $\$ 80.00$ per visit & RAMQ (14) \\
\hline Nurse, first visit ${ }^{*}$ & $\$ 32.63$ per visit & FIQ (13) \\
\hline Nurse, follow-up ${ }^{\dagger}$ & $\$ 8.16$ per visit & FIQ (13) \\
\hline Laboratory testing, first visit & $\$ 529.20$ per visit & Belval (15) \\
\hline Laboratory testing, follow-up & $\$ 142.60$ per visit & Belval (15) \\
\hline Total first visit & $\$ 683$ & \\
\hline Total follow-up & $\$ 272$ & \\
\hline
\end{tabular}

ED

Overhead costs

\$215.17 per visit Annexe à la circu-

Physician, general practicioner ${ }^{\ddagger}$ Physician, specialist ${ }^{\S}$

Total

$\begin{array}{cc}\$ 65.75 \text { per visit } & \text { laire 2013-0 } \\ \text { RAMQ (14) } \\ \$ 139.85 \text { per visit } & \text { RAMQ (14) } \\ \$ 421 & \end{array}$

Inpatient care

Overhead costs

$\$ 1112.00$ per day Annexe à la circulaire 2013-028 (16)

Physician, general practitioner ED $\ddagger$ Physician, specialist ED§

Physician, specialist hospitalization $\pi$

Total

Social worker

$\$ 65.75$ per visit RAMQ (14)

$\$ 139.85$ per visit RAMQ (14)

$\$ 62.66$ per day RAMQ (14)

$\$ 1,407$

$\$ 64.68$ per hour Annexe à la circulaire 2013-028 (16)

Psychologist

$\$ 86.60$ per hour Annexe à la circulaire 2013-028 (16)

Antiretroviral therapy

$\begin{array}{lrl}\text { Pharmacist dispensing fee } & \$ 9.00 \text { per prescription } \\ \text { Atripla } & \$ 1,165 \text { per month } & \text { RAMQ (17) } \\ \text { Prezista } & \$ 855 \text { per month } & \text { RAMQ (17) } \\ \text { Norvir } & \$ 172 \text { per month } & \text { RAMQ (17) } \\ \text { Truvada } & \$ 783 \text { per month } & \text { RAMQ (17) } \\ \text { Intelence } & \$ 654 \text { per month } & \text { RAMQ (17) } \\ \text { Isentress } & \$ 690 \text { per month } & \text { RAMQ (17) }\end{array}$

${ }^{*}$ Average hourly wage of clinical nurse, specialized nurse practitioner, nurse practitioner candidate and nurse; ${ }^{\dagger}$ Calculated by dividing average hourly wage by average duration of follow-up visit (approximately $15 \mathrm{~min}$ ); ${ }^{\ddagger}$ Average fee of a simple visit and an elaborate visit; §Average fee of an internist, a cardiologist, a pneumologist and a microbiologist consult at the emergency department (ED); T/Average fee of an internist, a cardiologist, a pneumologist and a microbiologist consult during hospitalization. RAMQ Régie de l'assurance maladie du Québec; FIQ Fédération interprofessionnelle de la santé du Québec 
In summary, there are many potential benefits of 'on demand' PrEP. related strategy for non-IDU MSM at high risk for HIV acquisition, including its favourable cost-effectiveness ratio and its reasonably predictable long-term costs. Within the next few years, the first results of the IPERGAY clinical trial will become available. It will be interesting to find out if the 'on demand' strategy results in greater adherence to the prophylactic preexposure drug, increased number of averted infections and its subsequent economic impact.

\section{SUPPLEMENTARY TABLE 2}

Indirect cost: Average hourly wage weighted by age distribution of HIV infections*, 2012 \$

\begin{tabular}{lccrrr}
\hline & \multicolumn{3}{c}{ Age, years } & \\
\cline { 2 - 4 } & $\mathbf{1 5 - 2 4}$ & $\mathbf{2 5 - 5 4}$ & $\mathbf{2 5 5}$ & Reference \\
\hline Average hourly wage, $\$$ & 13.57 & 25.29 & 25.08 & CANSIM
\end{tabular}

\begin{tabular}{|c|c|c|c|c|}
\hline & & & & (23) \\
\hline Proportion of HIV infections, \% & 0.07 & 0.82 & 0.11 & INSPQ (22) \\
\hline Average hourly wage, weighted & & & & $\$ 24.44$ \\
\hline
\end{tabular}

by age distribution of

HIV infections

${ }^{*}$ Calculated by multiplying the proportion of HIV infections by the average hourly wage per age group. The results are then summed. CANSIM Statistics Canada socioeconomic database; INSPQ Institut national de santé publique du Québec
DISCLOSURES: MD is a postdoctoral fellow from the CIHR HIV Clinical Trial Network. JRG is recipient of a CIHR Frederick Banting and Charles Best Doctoral Award and of a Pfizer Post-Doctoral Mentorship Award. CT is a scholar from Fonds de la Recherche du Québec en Santé. CT is the Pfizer/University of Montréal Chair on HIV translational Research.

SOURCE OF SUPPORT: Grant from Réseau SIDA et Maladies Infectieuses du Fonds de la Recherche du Québec en Santé.

SUPPLEMENTARY TABLE 3 Indirect cost: Salary losses per HIV infection due to work absenteeism, 2012 \$

\begin{tabular}{lccc}
\hline & $\begin{array}{c}\text { Hours missed } \\
\text { per day of } \\
\text { work* }^{*}\end{array}$ & $\begin{array}{c}\text { Average annual } \\
\text { visits distributed } \\
\text { on sample }\end{array}$ & $\begin{array}{c}\text { Annual salary } \\
\text { losses per } \\
\text { patient }\end{array}$ \\
\hline Outpatient & 4 & $4^{\ddagger}$ & $\$ 391.10$ \\
Emergency department & 8 & 0.28 & $\$ 53.86$ \\
Social worker & 4 & 0.21 & $\$ 43.92$ \\
Psychologist & 4 & 0.45 & $\$ 20.94$ \\
Inpatient & 8 & 0.59 & $\$ 115.22$ \\
Total salary losses, $\$$ & & $\$ 625.05$ & \\
\hline
\end{tabular}

${ }^{*}$ Assumptions; ${ }^{\dagger}$ Calculated by multiplying average annual visits by average annual patients using the service and then by dividing this results by total number of patients; $¥$ Recommended number of follow-up visits per year; $\S$ Calculated by multiplying the average hourly wage weighted by age distribution (\$24.44) by the number of hours missed per day of work

SUPPLEMENTARY TABLE 4

Indirect cost: Salary losses per IPERGAY participant due to work absenteeism, 2012 \$

\begin{tabular}{|c|c|c|c|c|c|}
\hline & \multirow[b]{2}{*}{ Average hourly wage, \$ } & \multirow[b]{2}{*}{ Proportion of workers, $\%$} & \multicolumn{3}{|c|}{ Average hourly wage, weighted } \\
\hline & & & $\begin{array}{l}\text { General population } \\
\text { employment rate, } 2012\end{array}$ & $\begin{array}{l}\text { by employment rate and } \\
\text { proportion of workers }\end{array}$ & Wage losses, \$ \\
\hline \multicolumn{6}{|l|}{ Age, years } \\
\hline $25-54$ & 25.29 & 0.68 & 0.838 & 14.41 & 345.87 \\
\hline$\geq 55$ & 25.08 & 0.18 & 0.352 & 1.59 & 38.14 \\
\hline Total salary losses & & & & & 407.55 \\
\hline
\end{tabular}

CANSIM Statistics Canada socioeconomic database

SUPPLEMENTARY TABLE 5

Indirect cost: Salary losses per HIV infection due to employment rate gap, 2012 \$

\begin{tabular}{|c|c|c|c|c|c|c|}
\hline & $\begin{array}{c}\text { HIV age } \\
\text { distribution }\end{array}$ & $\begin{array}{c}\text { HIV-positive MSM } \\
\text { employment rate, } 2010\end{array}$ & $\begin{array}{c}\text { General population } \\
\text { employment rate, } 2010\end{array}$ & $\begin{array}{l}\text { Employment } \\
\text { rate gap }\end{array}$ & $\begin{array}{c}\text { Average annual } \\
\text { salary, } \$\end{array}$ & $\begin{array}{c}\text { Annual salary losses } \\
\text { per patient, } \$\end{array}$ \\
\hline \multicolumn{7}{|l|}{ Age, years } \\
\hline $15-24$ & 0.07 & 43.80 & 56.90 & 0.13 & 20,566 & 189 \\
\hline $25-54$ & 0.82 & 56.10 & 82.80 & 0.27 & 48,546 & 10,655 \\
\hline$\geq 55$ & 0.11 & 33.20 & 34.80 & 0.02 & 46,681 & 80 \\
\hline Total salary losses & & & & & & $10,925^{\star}$ \\
\hline Reference & INSPQ (22) & A Burchell & CANSIM (19) & & & CANSIM (23) \\
\hline
\end{tabular}

(personal communication,

April 30, 2013)

${ }^{*}$ Calculated by multiplying the employment rate gap by the proportion of HIV infections by the average annual salary per age group. The results are then summed. CANSIM Statistics Canada socioeconomic database; INSPQ Institut national de santé publique du Québec; MSM Men who have sex with men

\section{REFERENCES}

1. Sullivan PS, Hamouda O, Delpech V, et al. Reemergence of the HIV epidemic among men who have sex with men in North America, Western Europe, and Australia, 1996-2005. Ann Epidemiol 2009; 19:423-31.

2. Public Health Agency Canada. Summary: Estimates of HIV prevalence and incidence in Canada, 2011. Centre for Communicable Diseases and Infection Control: 2012;9.

3. Van Damme L, Corneli A, Ahmed K, et al. Preexposure prophylaxis for HIV infection among African women. N Engl J Med 2012;367:411-22.
4. Grant RM, Lama JR, Anderson PL, et al. Preexposure chemoprophylaxis for HIV prevention in men who have sex with men. N Engl J Med 2010;363:2587-99.

5. Thigpen MC, Kebaabetswe PM, Paxton LA, et al. Antiretroviral preexposure prophylaxis for heterosexual HIV transmission in Botswana. New Engl J Med 2012;367:423-34.

6. Paltiel AD, Freedberg KA, Scott CA, et al. HIV preexposure prophylaxis in the United States: Impact on lifetime infection risk, clinical outcomes, and cost-effectiveness. Clin Infect Dis 2009;48:806-15. 
7. Walensky RP, Ross EL, Kumarasamy N, et al. Cost-effectiveness of HIV treatment as prevention in serodiscordant couples. N Engl J Med 2013;369:1715-25.

8. U.S. National Institutes of Health. On demand antiretroviral preexposure prophylaxis for HIV infection in men who have sex with men (IPERGAY). U.S. National Institutes of Health. $<$ http://clinicaltrials.gov/ ct2/show/NCT01473472?term =Ipergay\& rank $=1>$ (Accessed July 2014).

9. Drummond MF, Sculpher MJ, Torrance GW, O’Brien BJ, Stoddart GL. Methods for the Economic Evaluation of Health Care Programs, 3rdedn. New York: Oxford University Press, 2005.

10. Schackman BR, Metsch LR, Colfax GN, et al. The cost-effectiveness of rapid HIV testing in substance abuse treatment: Results of a randomized trial. Drug Alcohol Depend 2013;128:90-7.

11. CDC. [Internet] HIV Cost-Effectiveness. Center for Disease Control and Prevention (CDC). <www.cdc.gov/hiv/topics/ preventionprograms/ce/index.htm> (Accessed July 2014).

12. La Direction des Communications du ministère de la Santé et des Services sociaux. L'examen médical de l'adulte vivant avec le virus de l'immunodéficience acquise (VIH). Gouvernement du Québec; 2013;139.

13. FIQ. Convention collective. Fédération Interprofessionnelle de la Santé du Québec (FIQ) 20 mars 2011-31 mars 2015. p. 258.

14. Régie de l'assurance maladie du Québec. Manuel des médecins spécialistes. 2013;178.

15. Belval M. Laboratoires regroupés du CHUM. Centre Hospitalier de l’Université de Montréal; April 2013.

16. MSSS. Liste des taux applicables au 1er mai 2013. Annexe à la circulaire 2013-028 (03014219): Ministère de la santé et services sociaux du Québec (MSSS); May 2013;12

17. Régie de l'assurance maladie du Québec. Liste des médicaments. November 2013;909.

18. Lee FJ, Amin J, Carr A. Efficacy of initial antiretroviral therapy for HIV-1 infection in adults: A systematic review and meta analysis of 114 studies with up to 144 weeks' follow-up. PLoS One 2014;9:e97482

19. CANSIM. Table 282-0002- Labour force survey estimates (LFS), 2010 and 2012 employment and employment rate by sex and age group, annual. Statistics Canada. <www5.statcan.gc.ca/cansim/> (Accessed July 2014).

20. Carpenter CS. Sexual orientation, work, and income in Canada. Can J Econ 2008;41:1239-61.

21. ISQ. Taux d'emploi des hommes selon certains groupes d'âge, Québec, Ontario, Canada, 1976 à 2011: Institut de la statistique du Québec (ISQ). <www.stat.gouv.qc.ca/donstat/societe/march_travl_ remnr/parnt_etudn_march_travl/pop_active/b006_1976-2011.htm> (Accessed May 2013).

22. Institut national de santé publique du Québec. Programme de surveillance de l'infection par le virus de l'immunodéficience humaine (VIH) au Québec : cas cumulatifs 2002-2012. Laboratoire de santé publique du Québec; 2013;69.

23. CANSIM. [Internet] Table 282-0072 - Labour force survey estimates (LFS), wages of employees by sex and age group, annual. 2012. Québec. Statistics Canada. <www5.statcan.gc.ca/cansim/a26> (Accessed May 2013).

24. Antiretroviral Therapy Cohort Collaboration. Life expectancy of individuals on combination antiretroviral therapy in high-income countries: A collaborative analysis of 14 cohort studies. Lancet 2008;372:293-9.

25. Tengs TO, Lin TH. A meta-analysis of utility estimates for HIV/AIDS. Med Decis Making 2002;22:475-81.

26. CADTH. Guidelines for the economic evaluation of health technologies: Canada, 3rd edn. Ottawa: Canadian Agency for Drugs and Technologies in Health, 2006.

27. Walensky RP, Paltiel AD, Losina E, et al. Test and Treat DC: Forecasting the impact of a comprehensive strategy in Washington, DC. CID2010;51:392-400.

28. Weber J, Tatoud R, Fidler S. Postexposure prohylaxis, preexposure prophylaxis of universal test and treat: The strategic use of antiretroviral drugs to prevent HIV acquisition and transmission. AIDS 2010;24(Suppl 4):S27-S39.

29. Gardner EM, McLees MP, Steiner JF, et al. The spectrum of engagement in HIV care and its relevance to test-and-treat strategies for prevention of HIV infection. Clin Infect Dis 2011;52:793-800.

30. CDC. PrEP: A New Tool for HIV Prevention. <www.cdc.gov/hiv/ pdf/prevention_PrEP_factsheet.pdf> (Accessed April 2013).
31. WHO. Consolidated guidelines on HIV prevention, diagnosis, treatment and care for key populations. Switzerland: World Health Organization, 2014.

32. Krentz HB, Gill MJ. Cost of medical care for HIV-infected patients within a regional population from 1997 to 2006. HIV Med 2008;9:721-30.

33. Kingston-Riechers J. The Economic Cost of HIV/AIDS in Canada. Canadian AIDS Society; 2011;17.

34. Schackman BR, Gebo KA, Walensky RP, et al. The lifetime cost of current human immunodeficiency virus care in the United States. Med Care 2006;44:990-7.

35. West RR, McNabb R, Thompson AG, Sheldon TA, Grimley EJ. Estimating implied rates of discount in healthcare decision-making. Health Technol Assess 2003; 7:1-60.

36. Weinstein MC, Siegel JE, Gold MR, Kamlet MS, Russell LB. Recommendations of the Panel on Cost-Effectiveness in Health and Medecine. JAMA 1996;276:1253-8.

37. Walensky RP, Freedberg KA, Weinstein MC, Paltiel AD. Cost-effectiveness of HIV testing and treatment in the United States. Clin Infect Dis 2007;45(Suppl 4):S248-S254.

38. Gomez GB, Borquez A, Caceres CF, et al. The potential impact of pre-exposure prophylaxis for HIV prevention among men who have sex with men and transwomen in Lima, Peru: A mathematical modelling study. PLoS Med 2012;9:e1001323.

39. Desai K, Sansom SL, Ackers ML, et al. Modeling the impact of HIV chemoprophylaxis strategies among men who have sex with men in the United States: HIV infections prevented and costeffectiveness. AIDS 2008;22:1829-39.

40. Koppenhaver RT, Sorensen SW, Farnham PG, Sansom SL. The costeffectiveness of pre-exposure prophylaxis in men who have sex with men in the United States: An epidemic model. J Acquir Immune Defic Syndr 2011;58:e51-e52.

41. Juusola JL, Brandeau ML, Owens DK, Bendavid E. The cost-effectiveness of preexposure prophylaxis for HIV prevention in the United States in men who have sex with men. Ann Intern Med 2012;156:541-50.

42. Golub S, Kowalczyk W, Weinberger C, Parsons JT. Preexposure prophylaxis and predicted condom use among high-risk men who have sex with men. J Acquir Immune Defic Syndr 2010;54:548-55.

43. Eaton L, Kalichman SC. Risk compensation in HIV prevention: Implications for vaccines, microbicides, and other biomedical HIV prevention technologies. Curr HIV/AIDS Rep 2007;4:165-72.

44. Martin JN, Roland ME, Neilands T, et al. Use of postexposure prophylaxis against HIV infection following sexual exposure does not lead to increases in high-risk behavior. AIDS 2004;18:787-92.

45. Crepaz N, Hart TA, Marks G. Highly active antiretroviral therapy and sexual risk behavior: A meta-analytic review. JAMA 2004;292:224-36.

46. Liu AY, Vittinghoff E, Chillag K, et al. Sexual risk behavior among HIV-uninfected men who have sex with men participating in a tenofovir preexposure prophylaxis randomized trial in the United States. J Acquir Immune Defic Syndr 2013;64:87-94.

47. Thng C, Thorpe S, Schembri G, et al. Acceptability of HIV preexposure prophylaxis (PrEP) and associated risk compensation in men who have sex with men (MSM) accessing GU services. HIV Med 2012;13:84.

48. Baeten JM, Donnell D, Ndase P, et al. Antiretroviral prophylaxis for HIV prevention in heterosexual men and women. N Engl J Med 2012;367:399-410

49. Buchbinder SP, Liu AY. CROI 2014: New tools to track the epidemic and prevent HIV infections. Top Antivir Med 2014;22:579-93.

50. Brooks RA, Landovitz RJ, Kaplan RL, Lieber E, Lee SJ, Barkley TW. Sexual risk behaviors and acceptability of HIV preexposure prophylaxis among HIV-negative gay and bisexual men in serodiscordant relationships: A mixed methods study. AIDS Patient Care STDs 2012;26:87-94.

51. Hutchinson AB, Farnham PG, Dean HD, et al. The economic burden of HIV in the United States in the era of highly active antiretroviral therapy: Evidence of continuing racial and ethnic differences. J Acquir Immune Defic Syndr 2006;43:451-7.

52. CHMD. [Internet] Life tables - Male. Canadian Human Mortality Database (CHMD). <www.bdlc.umontreal.ca/chmd/prov/que/que. htm> (Accessed April 2013). 


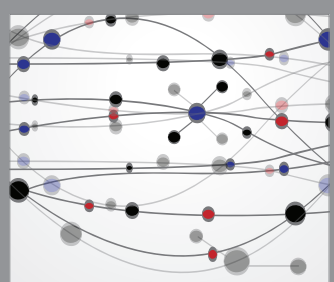

The Scientific World Journal
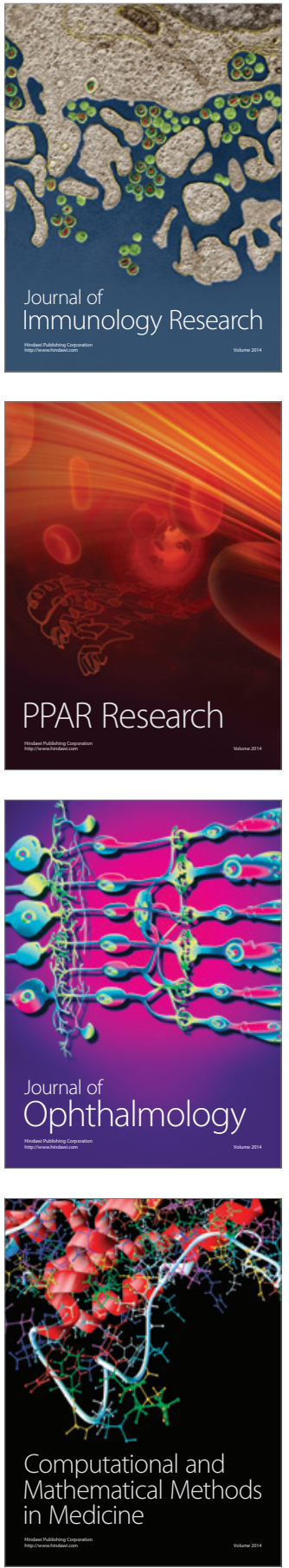

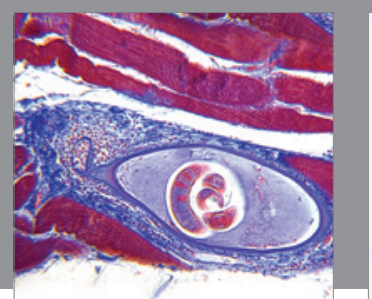

Gastroenterology Research and Practice

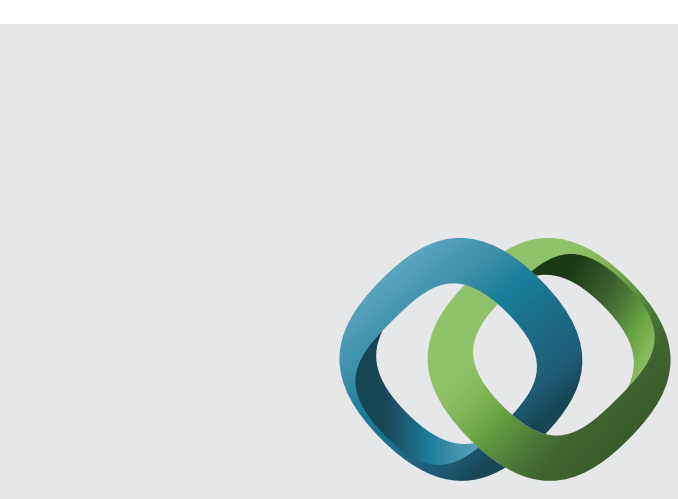

\section{Hindawi}

Submit your manuscripts at

http://www.hindawi.com
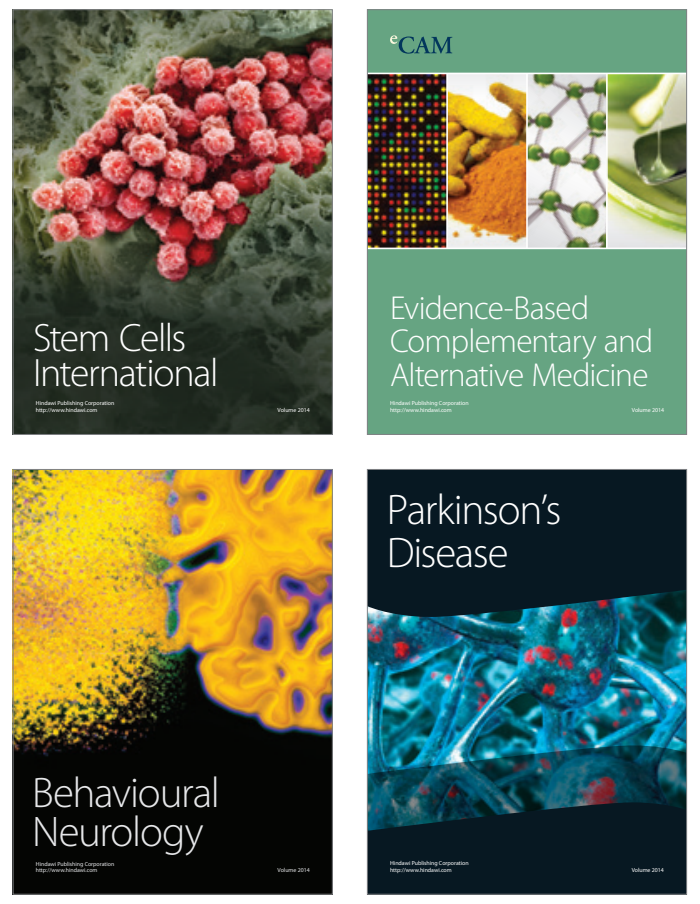
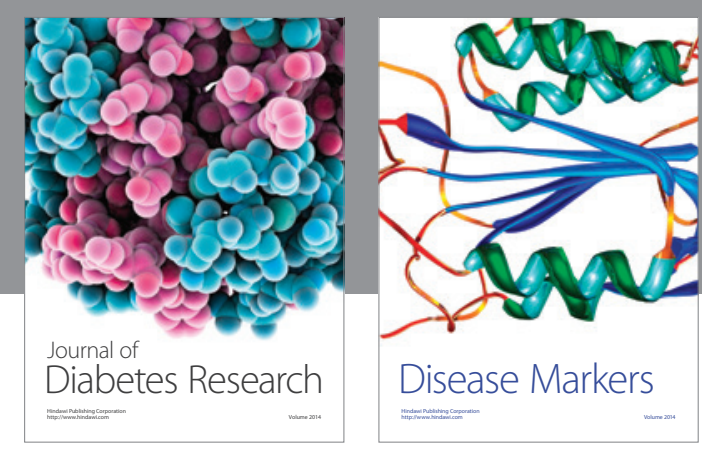

Disease Markers
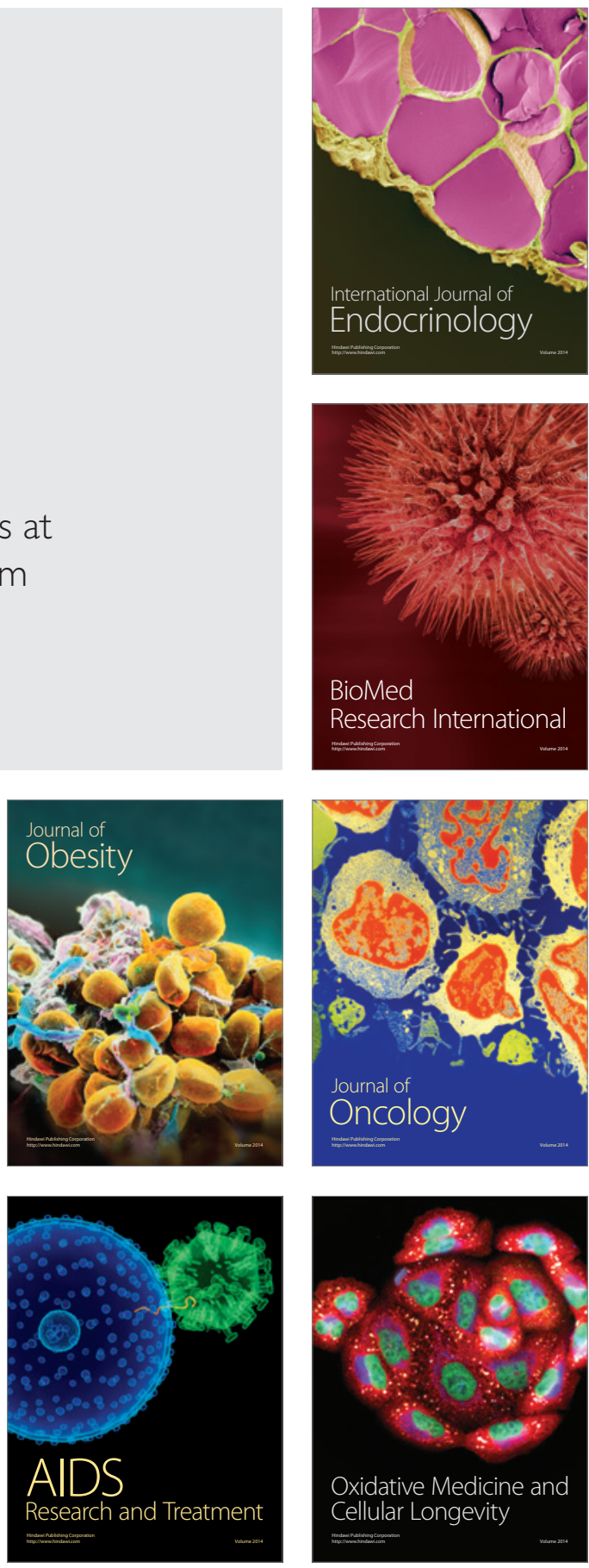